\title{
EFFICIENT SELF-SUSTAINED PULSED CO LASER
}

\author{
P.J.M. PETERS \\ Department of Applied Physics, Twente University of Technology, Enschede, The Netherlands
}

Received 30 January 1978

In this paper a simple sealed-off TEA CO laser is described with a self-sustained discharge without an external UV preionization source. At $77 \mathrm{~K}$ this system yields more than $600 \mathrm{~mJ}$ from a lasing volume of about $60 \mathrm{~cm}^{3} \mathrm{CO}_{-} \mathrm{N}_{2}-\mathrm{He}$ mixture (45 J/e atm, with $15.6 \%$ efficiency).

\section{Introduction}

As Cohn [1] indicated a homogeneously excited gain medium gives a remarkable increase in output energy and efficiency as compared to the conventional multipin discharge configuration. In this paper we present a relatively simple laser apparatus with solid electrodes and without an additional UV preionizing source. A similar device was reported by Ernst [2] for pulsed $\mathrm{CO}_{2}$ lasers. We have found that this technique is also very suitable for the cryogenically cooled $\mathrm{CO}$ laser. The output of more than $600 \mathrm{~mJ}$ from an active volume of $60 \mathrm{~cm}^{3}$ is one order of magnitude more than previously reported results with an UV preionized self-sustained discharge.

\section{Description of the system}

The experimental arrangement is shown in fig. 1 and fig. 2. The uniform field electrodes are made out of brass and profiled according a publication of Chang [3]. The separation of the electrodes is $10 \mathrm{~mm}$ and the discharge length is $60 \mathrm{~cm}$. The side-walls of the laser are formed by two brass plates, connected to the cathode and electrically isolated from the anode by two sheets of mylar having a thickness of $0.25 \mathrm{~mm}$ each (see fig. 2). The electrodes are placed in a pyrex tube. In order to minimize the temperature gradient in the active volume, caused by convection, both ends of the tube are provided with a perspex diaphragm of $15 \mathrm{~mm}$.

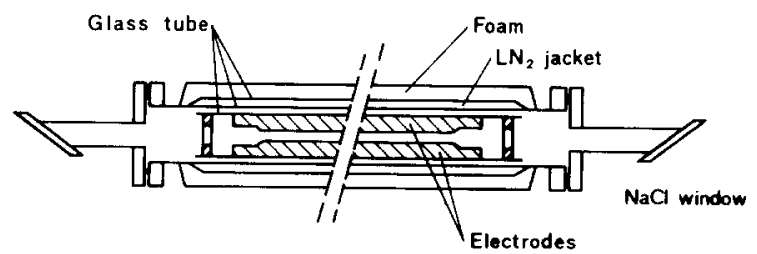

Fig. 1. Schematic set-up of the experimental configuration.

The whole laser cavity is placed in a double-walled, vacuum envelope of pyrex, which in its turn is surrounded by an insulation layer of foam. The electrical connections exist of stainless steel foils to minimize thermal conduction losses. The temperature in the active volume, measured with a $\mathrm{Cu}$ constantan thermocouple, is about $80 \mathrm{~K}$ and the temperature gradient is less than $10 \mathrm{~K}$. The optical cavity is formed by a $4 \mathrm{~m}$ radius of curvature total ( $\mathrm{Au}$-coated) reflector separated by $135 \mathrm{~cm}$ from a flat output mirror of $90 \%$ re-

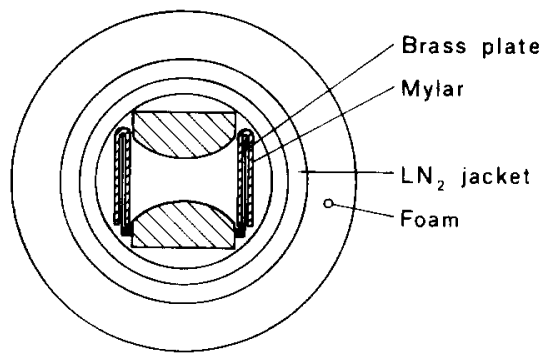

Fig. 2. Cross-section of the laser apparatus. 


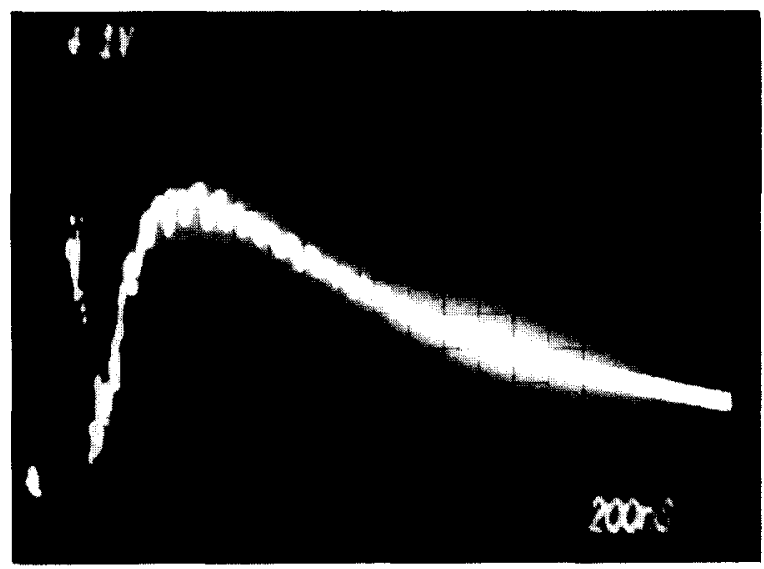

Fig. 3. This figure shows the current pulse through the laser. The time scale is $200 \mathrm{~ns} / \mathrm{div}$ ( $p=180$ torr, $\mathrm{CO}: \mathrm{N}_{2}: \mathrm{He}=1: 3: 7$ ).

flectivity. The $\mathrm{NaCl}$ brewster windows are separated by $130 \mathrm{~cm}$. The $1 \mathrm{~cm}$ square beam of radiation was detected either by a Joule meter, GenTec ED 500, or partially by an $\mathrm{InSb}$ detector at $300 \mathrm{~K}$. The gas was premixed before entering the laser tube and could be flowed. The system operates sealed-off. We did not observe any decrease in the pulse output energy after a great number of pulsed discharges. In fig. 3 the current pulse is shown. The prepulse of the current pulse can clearly be seen. This is due to the initial preionization pulse along the mylar sheets, which conditions the main discharge. The electrical scheme is shown in fig. 4. It is well-known that for increasing output energy and efficiency the $E / N$ value has to be decreased. For this purpose we used a resistance $R$ in series with the laser. Then we had initially a high voltage pulse over the electrodes and consequen tly high UV production for conditioning the main discharge. The

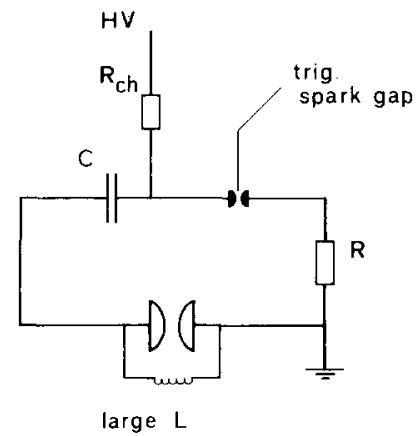

Fig. 4. Scheme of the electrical circuit $(C=4.5-100 \mathrm{nF}, R=$ $5-150 \Omega)$.
$E / N$ value of the main discharge is limited by $R$ and can in principle be adjusted to the best value. It is observed that with this series resistance the laser voltage appeared to be almost independent of the input voltage for most of the gas mixtures used. However, for constant input energy we observe the voltage over the laser to decrease with decreasing values of the capacitor.

\section{Experimental results}

By using a suitable capacitor (from 4.5-80 nF) and gas mixture stable discharges are possible in the region from 10 torr to atmospheric pressure. We studied so far the following systems: pure $\mathrm{CO}$, mixtures of $\mathrm{CO}-\mathrm{He}$, mixtures of $\mathrm{CO}-\mathrm{N}_{2}$, and mixtures of $\mathrm{CO}-\mathrm{N}_{2} \cdot \mathrm{He}$. They will be discussed in sequence.

\section{1. $\mathrm{CO}$}

At high pressure the total length of the output pulses is about $4 \mu$ s and the delay with respect to the discharge current pulse is about $1 \mu \mathrm{s}$. When the pressure is below 50 torr the number of output pulses is increasing and consequently the total pulse lengthens with time. Maximum output is $4 \mathrm{~mJ}$ at 75 torr.

\section{2. $\mathrm{CO}-\mathrm{He}$}

The total length of the output pulses varies from $4 \mu \mathrm{s}$ at high pressure, high CO concentration and low input energy to more than $3 \mathrm{~ms}$ at low pressures, high input energy and low $\mathrm{CO}$ concentration. Maximum output was $150 \mathrm{~mJ}$ for a $\mathrm{CO}-\mathrm{He}=1: 4$ mixture at 150 torr.

\section{3. $\mathrm{CO}-\mathrm{N}_{2}$}

Apart from a pulse immediately after the excitation pulse, due to directly excited $\mathrm{CO}$ molecules, we observe that the delay time between the onset of lasing and the excitation pulse is getting longer for higher pressure, lower input energy and higher $\mathrm{N}_{2}$ concentrations. The total pulse length increases with higher input energy, lower pressure and also with higher $\mathrm{N}_{2}$ concentration. Maximum output was $200 \mathrm{~mJ}$ with a $\mathrm{CO}-\mathrm{N}_{2}=1: 6$ mixture at 80 torr. 


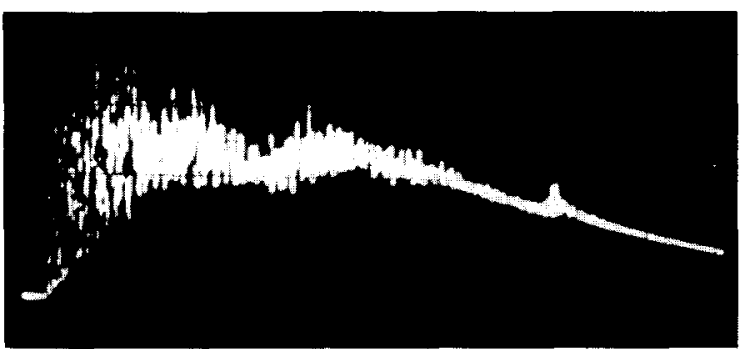

Fig. 5. Output pulse measured by the InSb detector. The time scale is $200 \mu \mathrm{s} /$ div ( $p=180$ torr, $\mathrm{CO}: \mathrm{N}_{2}: \mathrm{He}=1: 6: 6$ ).

\section{4. $\mathrm{CO}-\mathrm{N}_{2}-\mathrm{He}$}

In this gas mixture the delay time and total pulse length vary in the same way with the concentration of $\mathrm{N}_{2}$ and $\mathrm{He}$ as in the mixtures of $\mathrm{CO}-\mathrm{N}_{2}$ and $\mathrm{CO}-\mathrm{He}$. For example, with a $\mathrm{CO}-\mathrm{N}_{2}-\mathrm{He}=1: 6: 6$ mixture we were able to measure a delay time of $600 \mu \mathrm{s}$ at 200 torr and a total pulse length of more than $10 \mathrm{~ms}$ at 75 torr. The laser output contains a series of successive pulses with a maximum intensity after some time. This time is very large (hundreds of $\mu \mathrm{s}$ ) for $\mathrm{N}_{2}$-rich mixtures and short (about $10 \mu \mathrm{s}$ ) for mixtures in which the $\mathrm{N}_{2}$ concentration is comparable with the $\mathrm{CO}$ concentration.

Another remarkable feature in the $\mathrm{N}_{2}$-rich mixtures is that the intensities of the output pulses suddenly increase after a number of decreasing pulse intensities. This is shown in fig. 5. The background in this figure is a heating effect of the InSb detector by the laser flux.

Until now we get the maximum output of $625 \mathrm{~mJ}$ with a $\mathrm{CO}: \mathrm{N}_{2}: \mathrm{He}=1: 2: 8$ mixture and $C=80 \mathrm{nF}, V_{\mathrm{R}}$ $=15 \mathrm{kV}, V_{\text {laser }}=-5 \mathrm{kV}(R=25 \Omega)$. The pressure is 178 torr. This corresponds to an efficiency of $15.6 \%$.

\section{Conclusions}

The preliminary results reported here show that our system is superior to other self-sustained systems reported earlier $[1,4]$. The discharge is stable over a broad pressure range with different gas mixtures. Furthermore high input densities of about $0.5 \mathrm{~kJ} / \ell$ atm. at $80 \mathrm{~K}$ can be achieved. Also the series resistance is very important because it limits the currents through the laser and the voltage drop over the laser. This in its turn provides a low $E / N$ value and consequently a high fractional electron power transfer to vibrational excitation of $\mathrm{CO}$ and $\mathrm{N}_{2}$ molecules $[5,6]$.

\section{References}

[1] D.B. Cohn, IEEE J. Quantum Electr., QE-10 (1974) 459.

[2] G.J. Ernst, Thesis, Twente University of Technology, Enschede, The Netherlands (1977).

[3] T.Y. Chang, Rev. Scient. Instr. 44 (1973) 405.

[4] L. Champagne, Appl. Phys. Letters 23 (1973) 158.

[5] W.L. Nighan, Appl. Phys. Letters 20 (1972) 96.

[6] W.L. Nighan, Phys. Rev. A 2 (1970) 1989. 